\title{
What's the Story on Agriculture? Using Narratives to Understand Farming Households' Aspirations in Meru, Kenya
}

\author{
Luke Dilley $^{1,2} \cdot$ Kai Mausch ${ }^{2}$ - Mary Crossland ${ }^{3}\left(D \cdot\right.$ Dave Harris $^{3,4}$
}

Accepted: 16 January 2021 / Published online: 15 February 2021

(C) The Author(s) 2021

\begin{abstract}
In the limited research on farming aspirations, little attention has been paid to the narratives which frame and shape them, and the ways in which the aspirations of those who farm intersect with the goals of extension services. Drawing on multimethod research conducted in Meru County, Kenya, we demonstrate how aspirations are not only situated within a consideration of personal circumstances, but are shaped in crucial ways by networks of relations and by the perceived possibilities afforded by material and cultural resources. We further highlight the accounts of state extension agents that link a lack of engagement with the desires and needs of those who farm to the failure of agricultural development initiatives. We argue that an engagement with aspirations opens up a route to understanding the obstacles and potentialities that matter to those who farm and, as such, might enable more responsive development initiatives centred on the perceptions and desires of those who farm.
\end{abstract}

Keywords Agency · Extension services · Adoption · Livelihood strategies

\section{Résumé}

Dans les études - limitées - sur les aspirations dans le monde agricole, on a accordé peu d'attention aux récits qui les encadrent et les façonnent, et aux façons dont les aspirations des personnes qui travaillent dans l'agriculture se recoupent avec les objectifs des services de vulgarisation. En nous appuyant sur des études aux méthodes mixtes menées dans le comté de Meru, au Kenya, nous démontrons que les aspirations ne s'inscrivent pas seulement dans le cadre de circonstances personnelles, mais

Luke Dilley

dillwhap@gmail.com

1 Akita International University, Akita, Japan

2 World Agroforestry (ICRAF), Nairobi, Kenya

3 School of Natural Sciences, Bangor University, Bangor, UK

4 International Crops Research Institute for the Semi-Arid Tropics (ICRISAT), Nairobi, Kenya 
sont façonnées de façon significative par les réseaux de relations et par les opportunités perçues en fonction les ressources matérielles et culturelles disponibles. Nous relayons également les témoignages d'agents publics de vulgarisation qui attribuent l'échec des initiatives de développement agricole au manque de prise en compte des désirs et des besoins des personnes qui travaillent dans l'agriculture. Nous soutenons que la prise en compte des aspirations ouvre la voie à la compréhension des obstacles et des potentialités qui comptent pour les personnes qui travaillent dans l'agriculture et qu'à ce titre, elle pourrait permettre des initiatives de développement plus réactives centrées sur les perceptions et les désirs des travailleurs agricoles.

\section{Introduction}

The adoption of new agricultural technologies and practices has been at the core of a broad range of development initiatives and is widely seen as a key means by which to reduce poverty and hunger (Dercon et al. 2007; Pingali et al. 2006). However, notwithstanding a number of successes, adoption of technologies and sustainable farming practices within sub-Saharan Africa is below expectations despite the apparent potential benefits to farmers (Jerneck and Olsson 2013; Spielman and Smale 2017). To date, research on adoption has commonly been underpinned by a view of farming technologies as a transferable box, with adoption being viewed as a mechanistic and binary process (Glover et al. 2019). Adoption is subsequently understood as the outcome of the intersection of a variety of extrinsic factors conceptualised either in terms of facilitators of, or barriers to, adoption (Sumberg 2005). These studies in turn are often grounded upon assumptions of formal rationality, meaning that farmers are thought to make decisions based upon an economic assessment of means and ends (Vanclay and Lawrence 1994). As a consequence, many adoption studies overlook the broader livelihood strategies of many who farm (Dorward 2009; Dorward et al. 2009) and the ways in which adoption is embedded in complex social processes (de Wolf 2010; Glover et al. 2016). Further, failure to utilise certain agricultural technologies or practices is commonly attributed to a lack of knowledge, a range of different extrinsic barriers (Verkaart et al. 2019) or, more recently, cognitive failings that are themselves seen to be exacerbated by poverty (Duflo et al. 2011; Kremer et al. 2019). The outcome of such framings are analyses of decision-making in which other substantive considerations, such as the goals, wants and aspirations of those who farm, largely disappear from view. Recent work in Africa has, however, begun to focus on aspirations, particularly on the ways in which farming practices intersect with rural people's aspirations and livelihood goals (Mausch et al. 2018; Verkaart et al. 2018). This work moves away from the (ir)rationalistic framings of adoption, and not only resonates with recent calls for a more agent-orientated conceptualisation of technological adoption (Glover et al. 2019), but also provides insights into a potentially crucial, but often overlooked, aspect of agricultural adoption. Notably, the desires and hopes of those who farm and what they aspire to do and, indeed, who they aspire to be. 
While the current, but limited, scholarship on farming aspiration represents a valuable point of departure, there is still much that has been under- and un-explored. Is agriculture aspirational in households that farm and which farming strategies do households wish to pursue? What are the narratives that frame and shape farming aspirations? How do farming aspirations intersect with the goals of agricultural and development initiatives? This exploratory study seeks to begin to address these questions in the context of calls for agricultural development agencies and practitioners to take a greater account of the desires of rural households. To do so, this paper is structured as follows. We first discuss some of the current literature primarily in the field of agricultural development, and suggest that the work of Glover et al. (2019) represents a fruitful analytical framework through which to approach aspirations. Focusing on Meru County as a case example, we then go on to examine empirically the aspirations of those who farm, and the ways in which these aspirations intersect with the goals of local extension agents and activities. We demonstrate that agricultural aspirations are not only the outcome of an assessment of personal circumstances, but are shaped in crucial ways through social interactions and by the possibilities afforded by both cultural and material resources. Finally, we argue that our findings lend weight to the argument that agricultural extension activities could benefit from a consideration of aspiration not only in the planning and designing of support mechanisms and packages but also in their delivery.

\section{Background and Theory}

The recent scholarship on rural aspirations is beginning to draw attention to the wants and desires of those living in rural areas and has started to cast a light on an underexplored dimension of rural life within the development literature. We share the view within this scholarship that examining rural aspirations is important if we wish to develop a more rounded understanding of the life strategies and decision-making of those who farm (Mausch et al. 2018; Verkaart et al. 2018). This is because aspirations can be understood as visions of desired futures and scenarios (Flechtner 2017) and as crucial drivers that sit behind the formulation, development and setting in motion of particular courses of action. In this sense, aspirations can function as important transformational drivers that trigger particular strategies of action that aim to "contest, alter, and/or escape ... [current] (economic, social, and cultural) living conditions" (Castillo 2015, p. 91).

Recent literature has begun to explore and demonstrate the importance of aspirations in the life strategies of the rural poor. However, there has been a tendency within some of the literature to overemphasise the "individualistic properties of aspirations" (Bennike et al. 2020, p. 46). Such renderings of aspiration risk abstracting the individual from their context and reifying a rational economic agent who plays a determining role in "setting their aspirations" (Dalton et al. 2016, p. 166). Further, such analyses are in danger of reducing aspirations to another factor to be added to econometric models to explain technological adoption or the success or failure of development programmes (see: Mekonnen and Gerber 2017; Okello et al. 2019). Yet, crucially, we do not see aspirations as one might an individual preference, 
rather aspirations are understood as social in nature in that they are embedded and shaped by the materiality, practices, discourses and beliefs of a culture. In this rendering, aspirations are never simply the product of the atomised individual, but are "formed in interaction and in the thick of social life" (Appadurai 2004, p. 67).

Drawing on and adapting the language of Glover et al. (2019) arguably adds to this rendering of rural aspiration in the context of agriculture in fruitful ways. Here, aspirations of those who farm can be understood as linked firstly to affordances or the perceived opportunities afforded in a certain context. ${ }^{1}$ This perception of opportunities is both "situational and relational" (Ibid., p. 174) and connects to both material aspects of the physical environment and individual resources as well as to institutions, norms and expectations relating to what is appropriate. Aspirations are also tied to propositions and encounters (Glover et al. 2019): that is to say that novel ideas or concepts proposition the farmer and spark new imagined possibilities, or future farming strategies. Such propositions are usually located within encounters, the coming across of novel ideas or practices, either in formally organised contexts such as training days, or through media (Appadurai 2003), or less formally through gossip, discussions with other farmers, or simply observing one's neighbours. In this way, rural aspirations and the aspirations of those who farm are formed and framed within an 'opportunity space' understood as a "universe of more or less viable options" (Sumberg et al. 2012, p. 266; Sumberg and Okali 2013, p. 5) that is mediated by encounters and the possibilities afforded by the material and cultural.

By exploring the ways in which those who farm in India frame their aspirations to grow GM cotton and highlighting how these aspirations are linked into broader economic shifts, Flachs (2019) demonstrates the utility of moving away from an economic rationalist logic that is embedded in much literature on farming practices. However, studies to date in this vein which directly address farming aspiration have either focused on youth (see: Daum 2019) or on one particular crop and miss the broader (agricultural) aspirations of those who farm (see: Flachs 2019; Okello et al. 2019). Such a single crop focus potentially misses the ways in which aspirations (not) to pursue certain agricultural strategies may intersect or be mediated by other considerations including non-agricultural work or agricultural wage employment (although see Daum (2019) for a discussion in the context of youth). Another key aspect that much of the literature on farming aspirations has yet to engage with is the ways in which the aspirations of those who farm intersect with the strategies, policies and desires of those above (Bennike et al. 2020, p. 47). Specifically, while questions have been raised over the effectiveness of agricultural extension services in sub-Saharan Africa (Davis 2008) they are, nevertheless, understood to play an important role in translating policy objectives onto the ground (Funder and Mweemba 2019) and shaping the livelihood strategies of those who farm (Buehren et al. 2019; Norton and Alwang 2020; Verkaart et al. 2019). Despite this, there has to date been a lack of attention paid to how the aspirations of those who farm intersect with the goals of extension agents and their programmes.

1 Glover et al. (2019, p. 170) use the term "dispositions" rather than aspirations.

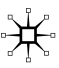


A previous lack of attention to the ways in which action, goals and needs are shaped within social interaction has been put forward as a reason for the failure of development projects and initiatives (Alkire 2004, p. 187). Subsequently, there have been calls for development agencies to understand and work with the grain of cultural beliefs, values and practices (Demeritt and Hoff 2019). Exploring and understanding the aspirations of those who farm resonates with these calls and potentially provides an entry point into the development of more tailored and targeted development interventions that respond to the "demands of rural households" (Verkaart et al. 2019, p. 31). The importance of our study relates to the ways in which aspirations and the stories which frame these aspirations can be understood as "diagnostic" as they embed a critique of the present and point to issues or areas of opportunity that can be explored (Bennike et al. 2020, p. 51). Thus, an understanding of aspirations could have important implications for agricultural development agencies, projects and initiatives.

\section{Method}

This paper draws on research that was conducted primarily in one of the sub-counties of Meru County, Kenya. ${ }^{2}$ The research was multimethod in nature and had three distinct components. The first component involved the use of SenseMaker®; a digital survey tool that is designed to help facilitate the generation of meaning and reduce researcher bias by capturing the survey respondents' own interpretation of a story he or she has told (Cognitive Edge undated). SenseMaker® has to date only been used in a handful of publicly documented studies (see: Bakhache et al. 2017; Milne 2015) and as such represents a relatively new approach to data collection. In this study, SenseMaker® was employed to document the stories told by rural householders about their aspirations and livelihood goals as well as the respondents' own interpretation of their stories. The second component involved interviews with those who had previously undertaken the survey with the aim of documenting more in-depth narratives that people told about their current situation and imagined futures. ${ }^{3}$ Here, narratives in their recounting are understood to structure, frame and shape the experience of the world. They are spatially, historically and culturally situated and yet individually told (Rapport and Overing 2000) enabling an insight into the ways in which aspirations are embedded within a broader context, while recognising that aspirations are shaped in important ways by personal circumstance. The third component of the research involved interviewing both local private sector and government extension agents based in Meru County. This third component sought to examine the ways in which local extension activities resonate with the aspirations of farmers from the point of view of extension agents themselves.

\footnotetext{
2 The exact location has been not been given in order to ensure anonymity.

${ }^{3}$ For clarity, we distinguish between stories and narratives. Stories were collected using Sensemaker ${ }^{\circledR}$, while the narratives were obtained from the semi-structured qualitative interviews.
} 


\section{Study Area}

Meru County is centrally located in Kenya, with relatively good transport links to Kenya's capital Nairobi. Although Mount Kenya dominates the southern end of Meru County, the altitude varies considerably from 300 to $5199 \mathrm{~m}$. Broadly, the county is made up of low-land semi-arid areas, and highland well-watered and fertile areas, although a broad range of micro-climates is to be found. Rainfall is also varied, with $300 \mathrm{~mm}$ annually in the low-land areas, to $2500 \mathrm{~mm}$ in the south eastern area (Meru County Government, undated). As a whole, Meru County has high levels of agricultural productivity, with predominantly rain-fed agriculture contributing, on average, to about $80 \%$ of household income (MoALF 2016). Bananas, maize, potatoes, coffee, tea, French beans, miraa ${ }^{4}$ and livestock are commonly found in Meru County with the average land holding for small-scale farmers being $1.8 \mathrm{ha}$; although there is considerable variation in farm size depending on the area (Hakizimana et al. 2017). While many who farm in Meru County do so for subsistence and limited commercial production on relatively small pieces of land, there are large scale commercial farms in a number of different locations throughout the county (Hakizimana et al. 2017).

\section{Survey and Stories}

The survey was conducted as part of a broader research project examining the aspirations amongst those who farm in Kenya. For the SenseMaker® survey, 10 villages were randomly selected within the targeted sub-county of Meru County, with 10 households selected randomly from each of these villages. The household head along with either one randomly chosen spouse or child was also surveyed. To try and capture respondents' aspirations, each person was asked to imagine their "life in 10 years' time, tell a story about how you got to that point from this present day". This question was deliberately open ended and was phrased in a way not to suggest any particular livelihood focus. The following questions employed a broad mix of formats that sought to enable the respondent to self-assess certain elements of their story. The paper here focuses on the survey stories as told by the respondents about their future, as well as two questions related to: (1) the period of time the respondent envisaged farming in their imagined future; and, (2) the perception of risk and reward of crops and livestock. ${ }^{5}$ The survey was carried out by trained enumerators using a digital tablet and subsequently translated from the local language into English. In total 184 individuals were surveyed.

\footnotetext{
${ }^{4}$ Miraa, or khat, is a leaf that is chewed producing a stimulant effect. Meru County is an important area for the production of miraa (see: Carrier 2008).

5 Respondents were presented with a graph with risk on the $\mathrm{x}$-axis and reward on the $\mathrm{y}$-axis. Using a digital tablet, respondents could place a marker on the graph to correspondent to their perception of risk and reward for crops and livestock in relation to their stories.
} 


\section{Interviews and Narratives}

Following the survey, two rounds of semi-structured, qualitative interviews were conducted with members of the households that had previously been surveyed. These interviews sought to complement the aspirational stories obtained using SenseMaker® by capturing more in-depth narratives relating to the respondents' current circumstances and future hopes. Questions were open ended in nature and related to current livelihood activities, future hopes and sources of help and inspiration, including extension services. The first round of interviews took place in May 2019, and the second in November 2019. The interviews were conducted by one of the authors and took place on the homesteads of the interviewees. Households were purposely selected to represent a range of different stories captured by the survey as well as survey answers related to demographics (age and gender). In total 15 semi-structured interviews (nine men and six women) were conducted across the two rounds of interviews. Thirteen of the interviewees were between the ages 25 and 55, with two being over 55. The average self-reported size of land holdings was 1.45 acres $(n=13)$, and the majority, eleven, of the respondents reported they were from the Meru tribe, with three identifying as Kikuyu and one Maasai. The interviews were conducted either in English or Swahili, with translation taking place in situ by a local guide. All interviews were recorded and fully transcribed with further translation being added if needed.

Alongside interviews with householders, interviews were conducted with two private and three public extension agents. One of the private extension agents worked for a Sacco (a form of cooperative organisation), the second was a retired government extension agent who had set up his own company and had established a demonstration farm. All of the public extension agents worked in the same sub-county, but were responsible for different wards. The interviews were conducted by one of the authors and were conducted in English. As with the interviews with the householders, the interviews with the extension agents were audio recorded and fully transcribed.

\section{Analysis}

The stories from the SenseMaker® survey were analysed using QDAMiner Lite 2. Story data were analysed in terms of whether the survey respondent wished to farm or continue farming, and the goal and direction of the desired farming aspiration. The quantitative aspects of the survey data presented in this paper were analysed with the $R$ software package. Interview transcripts were analysed with QDAMiner Lite 2, with a number of rounds of manual coding and thematic analysis.

\section{Results}

\section{Household Aspirations}

From the survey story data, a majority of those in Meru County envision a future which involved some agricultural activity (Fig. 1). However, significant 


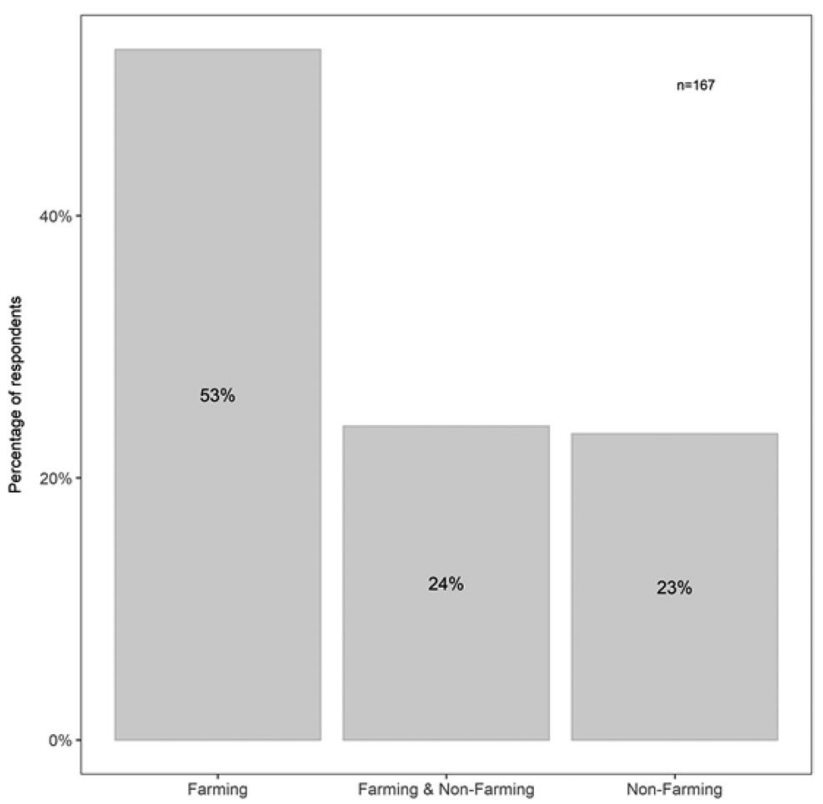

Fig. 1 Future livelihood aspiration. Data is derived from survey respondents' stories $(n=167)$

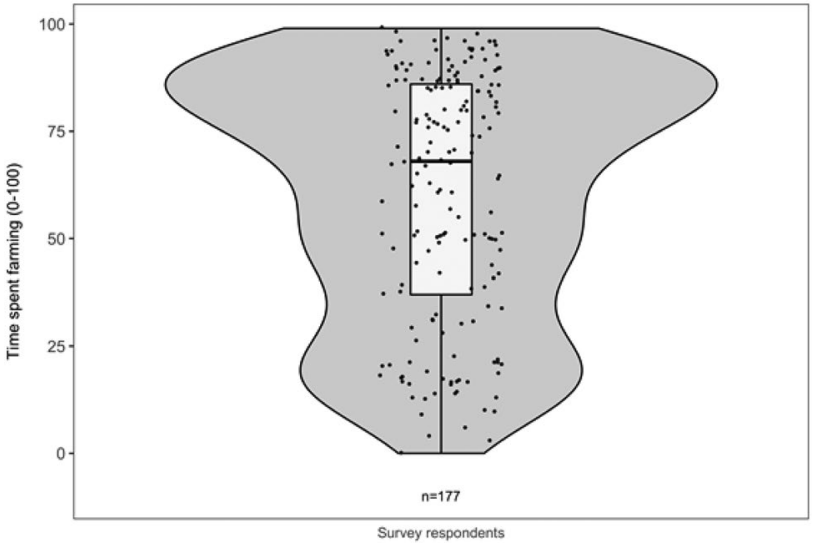

Fig. 2 Time spent farming in the future (0-100\%). Response to the prompt: 'In the story shared ... People spent all their time farming (100)_People spent all their time on other things (0)'. Dots represent individual responses, with the box representing upper and lower quartile and median $(n=177)$

proportions specifically mention either a combination of on- and off-farm (24\%), or only off-farm activities $(23 \%)$ when describing their imagined future. When asked about how much time they envisage they would spend farming in the future, very few imagine spending all their time farming or no time farming, with most indicating that they saw their imagined future involving a mix of activities (Fig. 2). Viewed together, Figs. 1 and 2 suggest that many in the study area wish 
Table 1 Future livelihood aspirational goals

\begin{tabular}{lcc}
\hline Farming goal & Cases & $\begin{array}{l}\text { Percentage } \\
\text { of cases }\end{array}$ \\
\hline Livestock: dairy & 41 & 32.00 \\
Farming: generic & 35 & 27.30 \\
Livestock: generic & 29 & 22.70 \\
Crop: generic & 21 & 16.40 \\
Livestock: chickens & 20 & 15.60 \\
Crops: vegetables generic & 5 & 3.90 \\
Livestock: cattle & 4 & 3.10 \\
Other: fruits generic & 4 & 3.10 \\
Trees: generic & 4 & 3.10 \\
Trees: miraa & 4 & 3.10 \\
Trees: avocado & 3 & 2.30 \\
Crops: French beans & 3 & 2.30 \\
Crops: cabbage & 2 & 1.60 \\
Trees: macadamia & 2 & 1.60 \\
Livestock: goat & 2 & 1.60 \\
Crops: potatoes & 1 & 0.80 \\
Other & 5 & 3.90 \\
\hline & & \\
\hline
\end{tabular}

Data is derived from survey respondents' stories who indicated that they envisaged farming activities in their future $(n=128)$. A story could mention a number of goals, so total cases equal more than 128

to engage with agricultural activities, but also hope that this will occur alongside other livelihood pursuits.

With regard to the goals of those survey respondents who mention agriculture, despite many mentioning farming in a generic sense, dairy farming is most commonly mentioned as a more specific goal (Table 1$).{ }^{6}$ Further, in looking at the direction of the respondents' aspirations, improving or starting dairy farming are the second and third most commonly mentioned aspirations (Table 2 ). ${ }^{7}$

Tables 1 and 2 both demonstrate a consistent reference to specific livestock, particularly dairy and chickens, and highlight a relative absence of reference to specific crops. While we might be able to infer that any reference to generic farming would include local staples, notably maize and potatoes (GOK and IFDA 2014), the relative lack of any specific mention of these staples apart from one person is of note (Table 1). Further, in examining the perceived reward gained from different types of

\footnotetext{
${ }^{6}$ If a respondent mentioned a particular activity as something they wanted to do in their story, this was determined to be a future goal.

7 A direction was able to be determined if the current circumstances of the survey respondent was clear, and the respondent gave enough details about how they saw themselves achieving their future. The direction of the respondents' stories could be determined in only $47 \%(60 / 128)$ of cases (Table 2$)$.
} 
Table 2 Future livelihood aspiration direction

\begin{tabular}{lc}
\hline Farming aspiration direction & No. of cases \\
\hline Improve/expand farming: generic & 15 \\
Improve livestock: dairy & 13 \\
Start livestock: dairy & 9 \\
Improve livestock: chickens & 7 \\
Improve crops/better yields: generic & 7 \\
Improve livestock: generic & 5 \\
Start trees: avocado and/or macadamia & 4 \\
Start crops: vegetables & 4 \\
Improve trees: generic & 3 \\
Start livestock: chickens & 3 \\
Improve livestock: cattle & 2 \\
Start livestock: generic & 2 \\
Other & 8 \\
\hline
\end{tabular}

Data is derived from survey respondents' stories $(n=60)$. A story could mention a number of directions, so total equals more than 60

farming, the data suggests that livestock in general is perceived as offering a greater reward but also a potentially greater risk (Fig. 3).

While such data provides us with an insight into the aspirations and perceptions of different types of on-farm activity, it is only through a more detailed examination of the narratives around farming obtained from interviews that we can build a more rounded picture of the aspirations of those who farm in Meru County.

\section{Affordances: Conditions of Possibility}

Milk production within Meru County has been positioned as a development opportunity by the Kenyan government and development agencies. The presence of the Meru Dairy Cooperative Union, a collection of some 73,000 farmers, provides residents of Meru County with an outlet for milk and with the planned expansion of milk processing capability in 2020, the market for milk appears to be increasing (Nzuri 2020). For two of the farmers interviewed, the affordance that the cooperative provided in terms of a good milk price and a more reliable market, was one reason behind a desire to expand and increase their dairy farming. This was in comparison to the frequently cited poor milk prices and unreliability of local middlemen and milk vendors. Margret noted that alongside a better milk price, selling to a cooperative is preferable:

because if you sell locally you are very uncertain whether you will be paid or not. Because if I take milk to a shopping centre here, it means that if this per- 


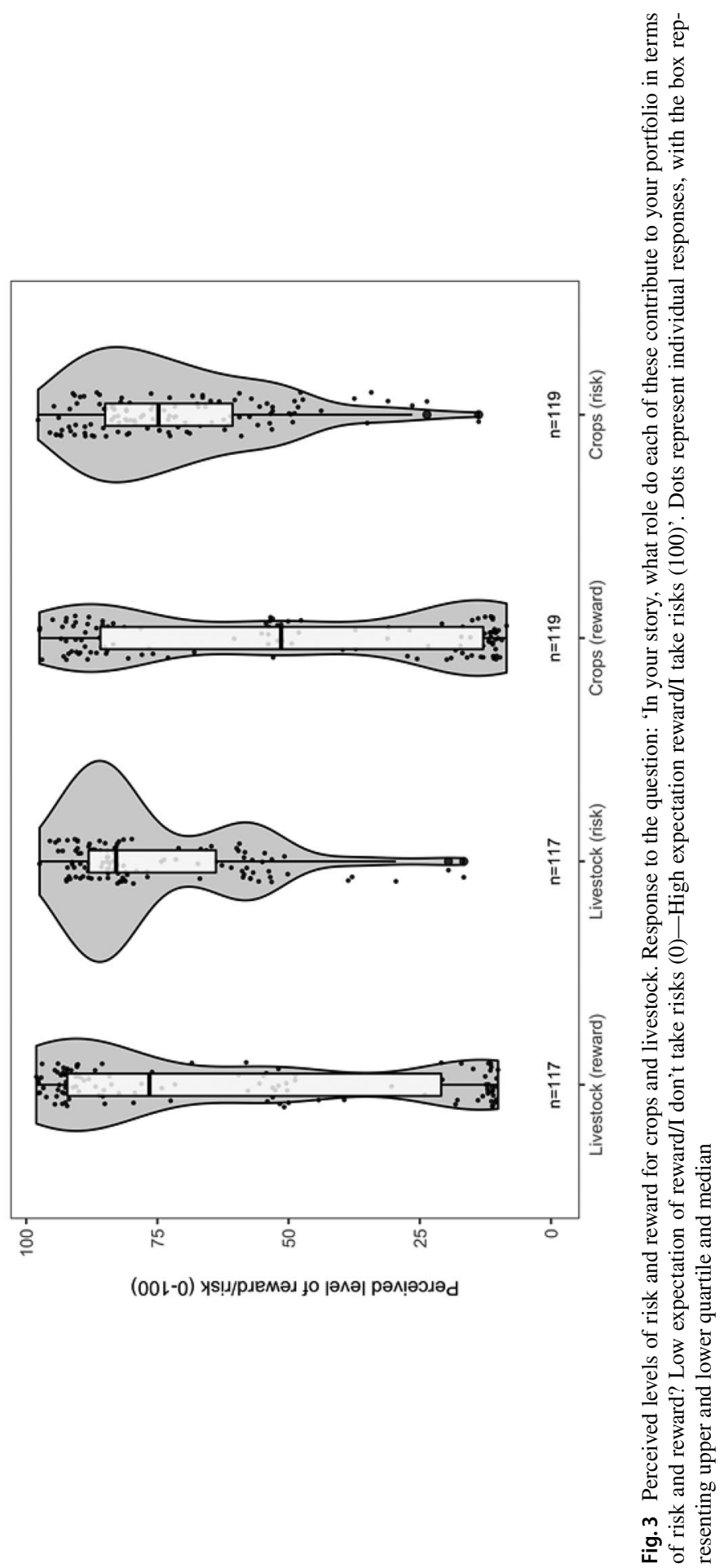


son closes his/her shop, if that milk ... is not kept well, it will be spoilt. And

... I won't be paid that day. (Margret, Farming Household) ${ }^{8}$

While the dairy cooperative can be perceived as a positive affordance, the desirability of dairy and livestock more generally can be understood in the context of a common framing of crop farming, particularly the local staples of potatoes and maize, as being unprofitable. For a number of the interviewees, this was partly due to pests and diseases and a perception that climatic conditions are becoming increasingly unpredictable. Rain-fed agriculture is by its nature heavily depended on sufficient rain, and hence poor rains can potentially have devastating consequences for a farmer's livelihood. While the majority of the interviewees have access to piped water, which some spoke about positively, the unpredictability of the supply and lack of adequate infrastructure such as drip lines meant that access to water did not decrease the risk of crop farming significantly. For Mark, a diversified income stream including employment and livestock was related to the inherent risk of crop production and was part of an effort to:

try and cushion the effect of the problems [of disease and lack of rain] by having a mixed enterprise. (Mark, Farming Household)

Diversification as a risk management strategy in the face of climatic shocks and other uncertainties has been noted elsewhere (Barrett et al. 2001; Niehof 2004). Yet, raising livestock also involves its own set of risks, and a number of the interviewees noted that they had lost livestock due to illness or disease. However, the apparent desirability of livestock, despite the perceived risks (Fig. 3) can be better understood in the context of a further disincentive surrounding crops, particularly maize and potatoes. This related to a reported lack of profit due to high costs of crop production, poor prices and exploitation by middlemen. For Purity the income derived from selling crops in comparison to investment in fertiliser and seeds meant that:

the farmer is not getting anything; they are just putting in resources and there is no income. (Purity, Farming Household)

This was in part due to a feeling that, particularly for potatoes due to the quick spoilage, farmers are forced to take low prices by middlemen who also arranged transport for the produce. Many of those interviewed argued that if they did not sell at the prices offered, they risked being left with produce that they would be unable to transport and sell themselves.

The difficulties surrounding crops, particularly the low reward, was a reason given for interviewee respondents favouring livestock, and a few had, in the current circumstances, either stopped commercial cropping of maize and potatoes or wished to stop and turn solely towards dairy. Lewis, for example, argued that exploitation by middlemen coupled with pests and insufficient rain meant that if he was able to buy dairy cows, he:

${ }^{8}$ All names are pseudonyms.

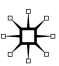


would stop doing anything about potatoes. (Lewis, Farming Household)

In similar terms to Lewis, crops were generally cast in a negative light, yet some did also see potential opportunities. Charles, like Lewis, also spoke about the difficulties associated with crop farming and yet for Charles, the local British Army base and tourist lodges potentially afforded a new avenue of opportunity. Charles, alongside a few others, was experimenting with cherry tomatoes and pak choi, produce not normally found in a Kenyan market, with the aim of growing and supplying the local expatriate community and tourist accommodation. Charles' aim was to exploit what he saw as an under-tapped and potentially lucrative market and in doing so generate more income than he would by selling staple crops locally.

While Charles' account could perhaps suggest that he is an example of that "rare operator" who can spot an opportunity others cannot (Sumberg and Okali 2013, p. 263), for Charles, Lewis and others, their desired futures are situated within narratives about the opportunity space afforded by broader market, climatic and agricultural conditions. However, it was also evident that aspirations are shaped and tempered by individual household circumstances in significant ways. For Makena, her aspiration to farm for herself was linked to her father's status as a "big farmer" (Makena, Farming Household), yet her ability to set in motion steps to reach this aspiration was profoundly shaped by her status as a squatter.

This land, let's say it is government land, we are squatters, in simple terms. We are not settled, we have no title deeds. [Because of this] you are just hanging, so you can't do anything, so even keeping livestock it is a problem because you don't know if it [eviction] will be today or tomorrow. Anything can happen, you don't know. (Makena, Farming Household)

For Makena, her lack of title deeds meant that investing in quality seed or livestock was not prudent as she could be dispossessed at any moment. This meant that Makena was also imagining livelihood possibilities outside of agriculture including hairdressing, and she had previously sold porridge at a small kiosk. This highlights how aspirations are closely linked to, tempered by and situated within narratives relating to the possibilities afforded by household circumstance. More broadly, Makena's account also draws our attention to not only the long history of dispossession and landlessness across Kenya (Hakizimana et al. 2017; Kanyinga 1998), but also the way in which opportunity spaces can be mediated by social position. As such, this suggests that aspirations are not divorced from wider social cleavages and historical processes, something that we begin to explore in more depth elsewhere (Crossland et al. this issue; Mausch et al. this issue).

Makena's account is of note because it firstly points to the ways in which opportunity spaces and aspirations are mediated by material circumstances that are themselves situated within broader historical and social processes. Secondly, the linking of Makena's desire to farm with her father's status as a big farmer suggests that social relations are important in the formation of visions of desired futures. Indeed, it was clear on speaking to others that informal networks acted as important sources of inspiration that render certain possibilities thinkable. 


\section{Propositions and Encounters}

The desired directions of those who farm are often informed by a network of familial and other relations. In speaking to the interview respondents about their aspirations, family, friends, neighbours as well as buyers and vendors of agricultural products were frequently mentioned as sources of information and ideas. Through encounters within this aggregate of relations, propositions spark thoughts related to new potential avenues for exploration and broaden the space of perceived opportunity. In particular, many of the interview respondents noted that family, friends and neighbours were a source of information on potentially successful strategies. Ndungu, who hopes to leave crop farming and focus on cattle and dairy, noted that:

there are farmers who are successful with cows around and they are doing well [and that he had] learnt a lot from them. (Ndungu, Farming Household)

Similarly, another respondent explained that:

what I learned from another place, from other farmers, I mixed it, so I use what comes up ... I ask my friends, I ask them who are selling to me, yeah, I ask them. (Muturi, Farming Household)

The second quote highlights the agency of those who farm in the adaptation and mixing of farming practices and technologies to their own vision, desires and needs (Glover et al. 2019; Jerneck and Olsson 2013). This adoption and adaptation is undertaken within a consideration of individual affordances, be it land size and availability, capital, skills and knowledge. Further, there were a few reports of active attempts to build on the knowledge gained through their local networks either through research on the internet, attending training days or agricultural shows. ${ }^{9}$ This was on occasion linked into a sense of pride at being in control of one's futures, and in making decisions about possible livelihood strategies. As one interviewee noted, he had "sufficient enough [ability] to do [his] own research" (Mark, Farming Household) and as such did not want advice on what enterprise to undertake.

The interview narratives point to the importance of propositions encountered within a network of relations in shaping the aspirations of those who farm in Meru County. These propositions render particular potential livelihood strategies and futures thinkable, and yet are mediated and adapted to fit the broader and personal affordances of those who farm. These, affordances are, however, not only related to material considerations, but also wider cultural beliefs about what is desirable.

If you compare animals and crops, actually animals are better ... They require a small space, the cost of maintenance is actually very minimal compared to the crops and even marketing wise, the animal itself is money ... [furthermore] It is actually interesting. [I am from the Meru tribe and for Merians] A home-

\footnotetext{
${ }^{9}$ One farmer noted that he went to agricultural shows and would wait until the end of the day when the cows were milked to assess whether the reported milk yields were actually true.
} 
stead without an animal is valueless. So we value animals ... If you do not have an animal, you actually do not have anything. (Francis, Farming Household)

Francis' ambition to expand his dairy farming is framed within a narrative which emphasises both material considerations relating to the size of his homestead as well as cultural beliefs around the necessity of livestock. Yet, culture is neither static nor a coherent monolith (Brumann 1999), and beliefs over the desirability of certain practices and products is a realm of disagreement and conflict. ${ }^{10}$ For Purity, her vision of increased miraa production was situated within and tempered by broader national and international debates about the status of miraa as an illegal narcotic (see: Carrier 2008). ${ }^{11}$

People are talking of miraa becoming a drug, but you know the government is saying miraa is a drug. Thus, we are just trying and see, you know if it can be a drug, now we are going to uproot all of it but if not, we continue with it. (Purity, Farming Household)

In this sense, a desired imagined future can be understood to be set in the context of material and (shifting) cultural affordances and informed by and formed within local and global networks and relations.

\section{Experimentation, Uncertainty and Suspicion}

The concept of affordances helps shed light on the ways in which an opportunity space and the aspirations of those who farm are shaped by social processes and the materiality of place. Further, attention to encounters and propositions draws out the way in which broader sets of relations are important sources of inspiration and information that spark and enable the visualisation of potential futures. However, with regard to propositions, experimentation and uncertainty are prominent themes that emerged from the interview data. This uncertainty and experimentation is related to both current livelihoods and potential future strategies. Purity for example noted that in the face of poor harvests and a lack of information:

I guess [about varieties] ... we usually look at it and say 'hey last year I planted 614 [maize variety] and it did not do well, so this time I am going to try 628 [maize variety], I am going to try this' ... like now this time, people have planted maize 614, it did not have many [produce much] ... now I believe next year they will not plant that, they will shift to another variety. (Purity, Farming Household)

\footnotetext{
${ }^{10}$ We would like to thank an anonymous reviewer for encouraging us to think about our conceptualisation of culture.

${ }^{11}$ At the time of writing, Somalia, an important market for miraa from Meru County, had put a blockade on the import of miraa.
} 
Henry, who is located at a relatively high elevation, suggested there was little information on which varieties of livestock and crops would do well at that altitude. He noted that this meant that many would talk to their neighbours and experiment with different varieties of crop and breeds of livestock that had been sourced at lower altitudes. When asked about the outcomes of this strategy, he noted that:

sometimes it was good, sometimes it is bad ... yeah just try, farming is like the game of get or I lost, yes, it is gambling. (Henry, Farming Household)

Hence while neighbours and other relations are important sources of inspiration, there is often uncertainty surrounding the propositions encountered within these networks which means that any new crop, breed or strategy necessitates a degree of experimentation and risk. While farming is of itself a risky and experimental endeavour, the uncertainty that surrounds potential and current livelihood opportunities is further linked to and compounded by a suspicion about the advice and products from private vendors and businesses. Particularly, there were reported suspicions about the advice being given by the vendors of agrichemicals, the claims being made about the products as well as the quality of seeds that were for sale.

The biggest challenge is the claims that they are making [i.e. agricultural vendors] is not really true, like they just repackage seeds that are not certified, for example, or they sell to you chemicals that do not really work. (Rose, Farming Household)

Although informal networks have for a long time been seen as important in the diffusion of beneficial agricultural technologies and practices (Coleman 1986) our data resonates with previous research which suggests that untrustworthy information from private vendors, coupled to a reliance on "environmental learning" and discussion with, and emulation of, other farmers" can result in considerable ambiguity over the benefits or suitability of a particular livelihood strategy (Stone and Flachs 2014, p. 650). Perhaps more importantly, the uncertainty and suspicion that emerged from the interviews problematises the notion embedded in much agricultural development literature that farmers will do, and will want to do, what is (economically) best as this first necessitates that those who farm have a clear understanding of "what choices will be best" (Flachs 2019, p. 57). The apparent difficulties that farmers have in discerning which potential strategies are best raises questions about the role of extension and advisory services, conventionally understood as important conduits of farming related advice and support.

\section{Extension Services and Aspiration}

Agricultural extension services, both private and public, are oriented to providing those who farm with reliable knowledge, advice and support (Anderson and Feder 2004). However, the sense of uncertainty and suspicion reported in the previous section emerged alongside an almost ubiquitous reporting of a lack of, or very limited contact with, state and private extension workers. One important factor to consider here is the move to a pluralist and demand-driven model of 
agricultural extension in Kenya (Kiara 2011; Ong et al. 2016). Within this model, an emphasis is placed on orienting extension services more towards the needs and desires of the farmer, and on the responsibility of those who farm to seek out and demand the services that they require (Anderson and Feder 2004; Norton and Alwang 2020). Despite this shift, and despite many farming interviewees stating that they wished to receive advice particularly on technical issues, the majority of interviewees noted that they had made few or limited attempts to access advisory services. For some of those interviewed, this was expressly linked to the costs of private services or a lack of a timely response from government extension agents to their previous requests.

This lack of a timely response was supported by government extension agents themselves, who noted the difficulties they had in visiting and providing advice to those who farmed within Meru County. This was primarily linked to low levels of staff and a lack of funding which meant that they do not have the vehicles or fuel to travel to meet farmers throughout the county (see also Funder and Mweemba 2019). This points to issues around resourcing and being able to meet the demands of individual farmers. However, it was also noted that there was commonly a lack of demand for the services they were able to offer, with one government extension agent stating that many farmers would not turn up to training days, while another remarked that he took steps to "trigger demand" (James, Public Extension Official).

The reported desire for information by those who farm, but a reported lack of engagement with extension agents resonates with Parkinson's (2009) findings that many farmers are ambivalent towards advisory services. Yet, James' comment points to a broader tension within government extension services that attempt to be more demand-driven, notably that a demand-driven model only works if there is demand for what you are able to offer, and in the absence of demand it becomes necessary to stimulate this demand. This then leads to questions related to how and what sort of demand is being stimulated.

For the government extension agents interviewed for this research, some of the project work they are involved in was less about responding to the demands of the farmers, but more a case of persuading those who farm to undertake a particular activity. When asked whether county or national initiatives met the needs of the farmers one extension agent noted that:

I would think that a lot of surveys are supposed to be done before implementing any project, anything ... but most of them are just brought down to the farmers, and the extension services are given the job to convince the farmers ... and some of it, even ourselves, we realise that it is not going to work. (Simon, Public Extension Official)

This assessment was supported by another agent.

[Often] it is top down approach ... we have always complained about it, you should ask the ... farmer so that you are able to design the project to favour them, so now if you come and tell the farmer to plant paw paws and the farmer is not interested, then the project shall fail, and that is what has 
made many projects fail, yah, because it is like imposing, you are dictating

to them, you have to do this. (Elanor, Public Extension Official)

An example that was given was a current initiative which sought to increase the production of macadamia nuts and avocado in the county which was said to be unpopular, a claim given weight by the survey data in which only five respondents specifically noted having these products as their goals (see Table 1). It was reported that this initiative was problematic because both of these crops required a large area and would take a number of years before they became financially productive. As found in other studies (Kairu et al. 2018), efforts were reported to have been made by the extension agents to negotiate between the interests of farmers and the goals of this particular initiative. And yet, while it was noted that there had been successful programmes and initiatives which had better incorporated farmers' desires in the past, the issue for extension workers was that many of the initiatives they were able to offer were driven by outside interests and reflected the (political) interests of these parties rather than the wants and desires of the farmers.

\section{Discussion}

Our research sought to explore: (1) the aspirations of those who farm in Meru County; (2) the narratives which enfold and shape these aspiration; and, (3) how these farming aspirations resonated and intersected with the agricultural adoption and extension initiatives at the local level. Our exploratory study demonstrates that the majority of those who farm in Meru County envisage a future in which they engage in agriculture, although it was clear that for many of the survey respondents (24\%), agriculture was envisaged as part of a broader set of on- and off-farm activities. The increasing importance of off-farm activities for rural livelihoods has been noted elsewhere (Rigg 2006), but our survey data suggests that a significant number of rural residents aspire to engage in non-agricultural income generating activities alongside their farming activities. In examining the formation of on-farm aspirations, our interview data sheds light on the ways in which the aspirations of those who farm emerge and are shaped within a complex of (perceived) affordances, encounters and propositions. In speaking to those who farm in Meru County, it is apparent that encounters, particularly within informal networks, are important sources of inspiration for the future, but visions of the future are themselves mediated by a host of interlinking material and (shifting) cultural affordances.

In particular, our results suggest that farming aspirations are shaped in important ways by a consideration of the potential of a range of farming activities. Of note was the prominence of the aspiration to engage in dairy farming, yet the desire to either expand or move into dairy farming is interlinked with a set of considerations relating to the desirability of a number of different crops given current market, climatic and agricultural conditions and their affordances. In this way, a desire to undertake a particular farming strategy is not divorced from a consideration of the broader farm system. This finding underscores the need to 
better understand the way in which the wants of those who farm are shaped by a consideration of the whole farm system (Almekinders et al. 2019) and points to a shortcoming in current research which commonly only focuses on farming aspirations in relation to one crop or farming strategy (Flachs 2019; Okello et al. 2019). As such, our study highlights how an agricultural related aspiration may well be linked into the perceived possibilities of one crop or strategy, but may also be linked in important ways to the supposed (im)possibilities of another.

Our findings also lend weight to the argument that taking account of the aspirations of those who farm could play a role in improving agricultural development projects and initiatives (Mausch et al. 2018; Verkaart et al. 2018). There were clearly issues related to the availability of resources with regard to both the ability of government extension agents to meet demand and for farmers to pay for services. This lack resources could be linked to the reported lack of engagement with extension initiatives. However, questions also emerged about the appeal of the extension services on offer. Specifically, government extension agents reported that, in their view, failure within some of the programmes and initiatives they had been tasked with delivering was linked to a top-down approach and a lack of a consideration of the desires of those who farm. This points to, despite the move to a demand-driven model of extension, an apparent and continuing disconnect between what development bodies, government agencies and technology developers offer and what farming households want given their heterogenous resource endowments and livelihood strategies (Almekinders et al. 2019; Gassner et al. 2019). Critiques related to a lack of accountability and lack of engagement with the needs of the farmer are not new and were part of the driver behind a transition to demand-driven models of extension (Anderson and Feder 2004). Yet, our findings suggest that, certainly in the case of the public extension services in Meru County which face resource constraints, a more explicit engagement with the heterogenous aspirations of those who farm within the schemes and initiatives that are on offer could help facilitate the transition towards more flexible, engaged and ultimately more effective extension and development activities.

Our research suggests that an agricultural development initiative focused around potatoes or maize which did not address a set of interrelated issues pertaining to land size, market and climatic conditions might not be attractive for many who farm in Meru County. However, the history of participatory approaches to agricultural development (Hauser et al. 2016) as well as the issues around 'participation' (Molosi-France and Dipholo 2019); 'the farmers voice' (Stone and Flachs 2014) and 'local knowledge' (Smith 2011) warns against any simplistic notion that a panacea for development would be to simply ask the farmer what they want to do. Indeed, our study highlights the difficulties those who farm had in knowing what was best; yet our exploratory study does point to the potential of engaging with the aspirations. This is for two reasons. First, as we have shown, aspirations provide an insight into the perceived affordances at the local and individual level which opens up further entry points for development initiatives and professionals to both address perceived obstacles and work with the grain of apparent potentialities. Second, in engaging with aspirations, the agency, creativity and desires of farmers are brought into focus, a recognition of 
which could facilitate a tailoring or targeting of initiatives to resonate with what rural residents want to do. However, this would seem to necessitate "discretionary and transaction-intensive" approaches to agricultural extension and development activities, something that would go against the grain of the current emphasis on scale and replicability (Pritchett and Woolcock 2004, p. 207).

\section{Conclusion}

Situated within recent adoption literature that has called for greater attention to be paid to both the agency and desires of those who farm, this exploratory study examined the aspirations of those who farm within Meru County, Kenya. In an attempt to move away from an individualistic framing of aspiration, this research utilised the framework put forward by Glover et al. (2019) through which we provide an account of aspirations as situated and framed within material and cultural affordances, encounters and propositions. We highlight the ways in which aspirations are not only embedded in an assessment of personal circumstances but are also shaped by a perception of the possibilities afforded by the material and social context. Further, we highlight how informal networks, and encounters within these networks, are important sources of inspiration that render thinkable possible desired futures. Finally, our findings lend weight to the argument that a greater consideration of aspirations could be instrumental in the development of more effective and engaged agricultural extension and development activities. We draw attention to the accounts of local government extension workers who, in part, link instances of failure within agricultural development initiatives to a lack of engagement with the desires of those who farm. We subsequently suggest that aspirations may be an important entry point that facilitates the development of more engaged, responsive and targeted agricultural extension and development activities.

This multi-method research was exploratory in nature and focused on a relatively small geographical area. As such, we are aware of its shortcomings in terms of representativeness and external validity. Nevertheless, in the context of agricultural development and adoption, our research has highlighted the potential of understanding aspirations, not with the end goal of raising aspirations and hoping farmers will pull themselves up by their bootstraps (Flechtner 2017), but rather because aspirations and understanding the ways in which they are embedded within social life and the materiality of context, offers a route towards comprehending and grappling with the issues and perceived possibilities that matter to those that farm. Further, engaging with the aspirations of the rural poor affords and recognises their agency, and could play an important role in the facilitation of development initiatives that are more responsive to the wants and desires of the intended recipients. On saying this, we recognise that engaging with aspirations will be far more complex than simply asking those who farm what they want. If aspirations are understood to be a potential route into improving the lives of the poor who farm, a lot more work will be needed to understand how this may be achieved. To this end, there are a number of areas that could be the focus of future work. First, with the apparent importance of informal networks, further analysis 
could focus on the key nodes and power dynamics within these networks to better understanding how they could expand or indeed close down opportunity spaces. Second, while we are beginning to explore this elsewhere, there are still many questions left to be explored relating to the ways in which aspirations intersect with social position. Finally, our exploratory study has only provided a snapshot of aspirations and as such, a longitudinal analysis that tracks shifts in aspirations, particularly in relation to the work of extension services, could prove fruitful.

Acknowledgements This work was undertaken as part of, and funded by, the CGIAR Research Program on Grain Legumes and Dryland Cereals (GLDC) and supported by CGIAR Fund Donors. We would like to thank all those who participated in this research. We would also like to thank two anonymous reviewers for their helpful and insightful comments. All errors remain our own.

\section{Compliance with Ethical Standards}

Conflict of interest The authors declare that they have no conflict of interest.

Open Access This article is licensed under a Creative Commons Attribution 4.0 International License, which permits use, sharing, adaptation, distribution and reproduction in any medium or format, as long as you give appropriate credit to the original author(s) and the source, provide a link to the Creative Commons licence, and indicate if changes were made. The images or other third party material in this article are included in the article's Creative Commons licence, unless indicated otherwise in a credit line to the material. If material is not included in the article's Creative Commons licence and your intended use is not permitted by statutory regulation or exceeds the permitted use, you will need to obtain permission directly from the copyright holder. To view a copy of this licence, visit http://creativecommons.org/licen ses/by/4.0/.

\section{References}

Alkire, S. 2004. Culture, poverty, and external validation. In Culture and public action, ed. V. Rao and M. Walton, 185-209. Palo Alto: Stanford University Press.

Almekinders, C.J., K. Beumer, M. Hauser, M. Misiko, M. Gatto, A.O. Nkurumwa, and O. Erenstein. 2019. Understanding the relations between farmers' seed demand and research methods: The challenge to do better. Outlook on Agriculture 48 (1): 16-21.

Anderson, J.R., and G. Feder. 2004. Agricultural extension: Good intentions and hard realities. World Bank Research Observer 19 (1): 41-60.

Appadurai, A. 2003. Archive and aspiration. In Information is alive, ed. W. Mass, A. Appadurai, J. Brouwer, and S.C. Morris, 14-25. Rotterdam: V_2 Publications.

Appadurai, A. 2004. The capacity to aspire: Culture and the terms of recognition. In Culture and public action, ed. V. Rao and M. Walton, 59-84. Palo Alto: Stanford University Press.

Bakhache, N., S. Michael, S. Roupetz, S. Garbern, C. Davison, S. Bartels, N. Bakhache, S. Michael, S. Roupetz, and S. Garbern. 2017. Implementation of a SenseMaker® research project among Syrian refugees in Lebanon. Global Health Action. https://doi.org/10.1080/16549716.2017.1362792.

Barrett, C.B., T. Reardon, and P. Webb. 2001. Nonfarm income diversification and household livelihood strategies in rural Africa: Concepts, dynamics, and policy implications. Food Policy 26 (4): 315-331.

Bennike, R.B., M.B. Rasmussen, and K.B. Nielsen. 2020. Agrarian crossroads: rural aspirations and capitalist transformation. Canadian Journal of Development Studies 41 (1): 40-56.

Brumann, C. 1999. Writing for culture. Current Anthropology 40 (S1): S1-S27.

Buehren, N., M. Goldstein, E. Molina, and J. Vaillant. 2019. The impact of agricultural extension services on women farmers' access, adoption and productivity: Evidence from Ethiopia. Agricultural Economics 50 (4): 407-419. 
Carrier, N. 2008. Is miraa a drug?: Categorizing Kenyan khat. Substance Use and Misuse 43 (6): 803-818.

Castillo, R. 2015. Landscapes of aspiration in Guangzhou's African music scene: Beyond the trading narrative. Journal of Current Chinese Affairs 44 (4): 83-115.

Cognitive Edge. Undated. About Sensemaker®. https://sensemaker.cognitive-edge.com/what-is-sense maker/. Accessed 18 Sept 2020.

Coleman, G.P. 1986. Innovation and diffusion in agriculture. Agricultural History 42 (3): 173-188.

Crossland, M., T. Pagella, K. Mausch, D. Harris, L. Dilley, and L.A. Winowiecki. This issue. Women's changing opportunities and aspirations amid male outmigration: Insights from Rural Kenya. The European Journal of Development Research.

Dalton, P.S., S. Ghosal, and A. Mani. 2016. Poverty and aspirations failure. Economic Journal 126 (590): 165-188.

Daum, T. 2019. Of bulls and bulbs: Aspirations, opinions and perceptions of rural adolescents and youth in Zambia. Development in Practice 29 (7): 882-897.

Davis, K.E. 2008. Extension in Sub-Saharan Africa: Overview and assesment of past and current models, future prospects. Journal of International Agricultural and Extension Education 15 (3): 15-28.

de Wolf, J.J. 2010. Innovative farmers, non-adapting institutions: A case study of the organization of agroforestry research in Malawi. In Beyond the biophysical, ed. L.A. German, J.J. Ramisch, and R. Verma, 217-239. Dordrecht: Springer.

Demeritt, A., and K. Hoff. 2019. The making of behavioral development economics. History of Political Economy 50 (1): 303-322.

Dercon, S., D.O. Gilligan, J. Hoddinott, and T. Woldehanna. 2007. The impact of roads and agricultural extension on consumption growth and poverty in fifteen ethiopian villages. American Journal of Agricultural Economics 91 (4): 1007-2021.

Dorward, A. 2009. Integrating contested aspirations, processes and policy: Development as hanging in, stepping up and stepping out. Development Policy Review 27 (2): 131-146.

Dorward, A., S. Anderson, Y.N. Bernal, E.S. Vera, J. Rushton, J. Pattison, and R. Paz. 2009. Hanging in, stepping up and stepping out: Livelihood aspirations and strategies of the poor. Development in Practice 19 (2): 240-247.

Duflo, E., M. Kremer, and J. Robinson. 2011. Nudging farmers to use fertilizer: Theory and experimental evidence from Kenya. American Economic Review 101 (6): 2350-2390.

Flachs, A. 2019. Planting and performing: Anxiety, aspiration, and "scripts" in Telangana cotton farming. American Anthropologist 121 (1): 48-61.

Flechtner, S. 2017. Should aspirations be a matter of policy concern? Journal of Human Development and Capabilities 18 (4): 517-530.

Funder, M., and C.E. Mweemba. 2019. Interface bureaucrats and the everyday remaking of climate interventions: Evidence from climate change adaptation in Zambia. Global Environmental Change 55: $130-138$.

Gassner, A., D. Harris, K. Mausch, A. Terheggen, C. Lopes, R. Finlayson, and P. Dobie. 2019. Poverty eradication and food security through agriculture in Africa: Rethinking objectives and entry points. Outlook on Agriculture 48 (4): 309-315.

Glover, D., J. Sumberg, and J.A. Andersson. 2016. The adoption problem; or why we still understand so little about technological change in African agriculture. Outlook on Agriculture 45 (1): 3-6.

Glover, D., J. Sumberg, G. Ton, J. Andersson, and L. Badstue. 2019. Rethinking technological change in smallholder agriculture. Outlook on Agriculture 48 (3): 169-180.

GOK and IFAD. 2014. Upper Tana Natutal Management Project. Baseline Survey Report. Government of Kenya and International Fund for Agricultural Development. http://www.utanrmp.or.ke/sites/all/modul es/pubdlcnt/pubdlcnt.php?file=http://www.utanrmp.or.ke/sites/default/files/downloads/UTaNRMP $\% 20$ Baseline\%20Survey\%20Report.pdf\&nid=132. Accessed 18 September 2020.

Hakizimana, C., P. Goldsmith, A.A. Nunow, A.W. Roba, and J.K. Biashara. 2017. Land and agricultural commercialisation in Meru County, Kenya: Evidence from three models. Journal of Peasant Studies 44 (3): 555-573.

Hauser, M., M. Lindtner, S. Prehsler, and L. Probst. 2016. Farmer participatory research: Why extension workers should understand and facilitate farmers' role transitions. Journal of Rural Studies 47: 52-61.

Jerneck, A., and L. Olsson. 2013. More than trees! Understanding the agroforestry adoption gap in subsistence agriculture: Insights from narrative walks in Kenya. Journal of Rural Studies 32: 114-125. 
Kairu, A., C. Upton, M. Huxham, K. Kotut, R. Mbeche, and J. Kairo. 2018. From shiny shoes to muddy reality: Understanding how meso-state actors negotiate the implementation gap in participatory forest management. Society \& Natural Resources 31 (1): 74-88.

Kanyinga, K. 1998. Politics and struggles for access to land: "Grants from above" and "squatters" in coastal Kenya. European Journal of Development Research 10 (2): 50-69.

Kiara, J.K. 2011. Focal area approach: A participatory community planning approach to agricultural extension and market development in Kenya. International Journal of Agricultural Sustainability 9 (1): $248-257$.

Kremer, M., G. Rao, and F. Schilbach. 2019. Behavioral development economics. In Handbook of behavioral eonomics: Applications and foundations 1, Volume 2, ed. B.D. Bernheim, S. DellaVigna, and D. Laibson, 345-458. New York: Elsevier B.V.

Mausch, K., D. Harris, E. Heather, E. Jones, J. Yim, and M. Hauser. 2018. Households' aspirations for rural development through agriculture. Outlook on Agriculture 47 (2): 108-115.

Mausch, K., D. Harris, L. Dilley, M. Crossland, T. Pagella, J. Yim, and E. Jones. This issue. Not all about farming: Understanding aspirations can challenge assumptions about rural development. European Journal of Development Research.

Mekonnen, D.A., and N. Gerber. 2017. Aspirations and food security in rural Ethiopia. Food Security 9 (2): 371-385.

Meru County Government. Undated. Meru County Integrated Development Plan, 2018-2022. Meru County Report. Meru County Government. http://meru.go.ke/lib.php?com=6\&com2=33\&\&res_id=885. Accessed 18 Sept 2020.

Milne, K.M.G. 2015. Can sense-making tools inform adaptation policy? A practitioner's perspective. Ecology and Society 20 (1): 66.

MoALF. 2016. Climate risk profile for Meru. Kenya County Climate Risk Profile Series. The International Center for Tropical Agriculture (CIAT) and the Kenya Ministry of Agriculture, Livestock and Fisheries (MoALF). https://cgspace.cgiar.org/bitstream/handle/10568/80454/Meru_Climate\%20Risk\%20Profile. pdf. Accessed: 18 September 2020.

Molosi-France, K., and K. Dipholo. 2019. Re-thinking participatory rural development in Botswana: Is the enemy in the theory or in the implementation process of the theory? The International Journal of Community and Social Development 1 (4): 295-309.

Niehof, A. 2004. The significance of diversification for rural livelihood systems. Food Policy 29 (4): 321-338.

Norton, G.W., and J. Alwang. 2020. Changes in agricultural extension and implications for farmer adoption of new practices. Applied Economics Perspectives and Policy 42 (1): 8-20.

Nzuri, R. 2020. Milking opportunity in the foothills of Mount Kenya. Avaliable at: https://blog.ciat.cgiar.org/ milking-opportunity-in-the-foothills-of-mount-kenya/. Accessed: 18 September 2020.

Okello, J., Y. Zhou, I. Barker, and E. Schulte-Geldermann. 2019. Motivations and mental models associated with smallholder farmers' adoption of improved agricultural technology: Evidence from use of quality seed potato in Kenya. European Journal of Development Research 31 (2): 271-292.

Ong, A.H., C.A. Onyango, and W.O. Ochola. 2016. Agricultural technology transfer among small-scale farmers: Case of Siaya County in Kenya. International Journal of Agricultural Extension. 04 (01): 57-69.

Rapport, N., and J. Overing. 2000. Social and cultural anthropology: The key concepts. London: Routledge.

Parkinson, S. 2009. When farmers don't want ownership: Reflections on demand-driven extension in SubSaharan Africa. The Journal of Agricultural Education and Extension 15 (4): 417-429.

Pingali, P., K. Stamoulis, and R. Stringer. 2006. Eradicating extreme poverty and hunger: towards a coherent policy agenda. ESA Working Paper. Food and Agricutural Organisation (FAO), 6, 1-18. Avaliable at: http://www.fao.org/3/a-af839t.pdf. Accessed 18 Sept 2020.

Pritchett, L., and M. Woolcock. 2004. Solutions when the solution is the problem: Arraying the disarray in development. World Development 32 (2): 191-212.

Rigg, J. 2006. Land, farming, livelihoods, and poverty: Rethinking the links in the Rural South. World Development 34 (1): 180-202.

Smith, T.A. 2011. Local knowledge in development (geography). Geography Compass 5 (8): 595-609.

Spielman, D.J., and M. Smale. 2017. Policy options to accelerate variety change among smallholder farmers in South Asia and Africa South of the Sahara. IFPRI Discussion Paper 01666. Internal Food Policy Research Insitute. Avaliable at: https://www.ifpri.org/cdmref/p15738coll2/id/131364/filename/13157 5.pdf. Accessed 22 Sept 2020.

Stone, G.D., and A. Flachs. 2014. The problem with the farmer's voice. Agriculture and Human Values 31 (4): 649-653. 
Sumberg, J. 2005. Constraints to the adoption of agricultural innovations. Outlook on Agriculture 34 (1): $7-10$.

Sumberg, J., N.A. Anyidoho, J. Leavy, D.J.H. te Lintelo, and K. Wellard. 2012. Introduction: The young people and agriculture "problem" in Africa. IDS Bulletin 43 (6): 1-8.

Sumberg, J., and C. Okali. 2013. Young people, agriculture, and transformation in Rural Africa: An "opportunity space" approach. Innovations: Technology, Governance, Globalization 8 (1-2): 259-269.

Vanclay, F., and G. Lawrence. 1994. Farmer rationality and the adoption of environmentally sound practices; A critique of the assumptions of traditional agricultural extension. European Journal of Agricultural Education and Extension 1 (1): 59-90.

Verkaart, S., K. Mausch, L. Claessens, and K.E. Giller. 2019. A recipe for success? Learning from the rapid adoption of improved chickpea varieties in Ethiopia. International Journal of Agricultural Sustainability 17 (1): 34-48.

Verkaart, S., K. Mausch, and D. Harris. 2018. Who are those people we call farmers? Rural Kenyan aspirations and realities. Development in Practice 28 (4): 468-479.

Publisher's Note Springer Nature remains neutral with regard to jurisdictional claims in published maps and institutional affiliations. 